\title{
The prevalence and risk factors for osteoporosis in patients with inflammatory bowel disease
}

\author{
Miznerova E, Hlavaty T, Koller T, Toth J, Holociova K, Huorka M, Killinger Z, Payer J \\ Department of Internal Medicine, Division of Gastroenterology and Hepatology, University Hospital and \\ Faculty of Medicine, Comenius University, Bratislava Ruzinov, Slovakia.ema.mizner@gmail.com
}

\begin{abstract}
Aim: Osteoporosis is a known chronic complication of inflammatory bowel diseases (IBD). The aim of our study was to describe the prevalence of reduced bone mineral density (BMD) in IBD patients and to identify crucial risk factors for osteoporosis.

Methods: The cohort consisted of 76 IBD patients, 40 with Crohn's disease (CD) and 36 with ulcerative colitis (UC). Clinical characteristics of every patient were recorded, i.e. age, sex, duration of the disease, clinical behavior, location of disease according to Montreal classification, surgeries, steroid medication, SIBDQ, and smoking habits. We examined the serum 25-hydroxyl vitamin D3 (25-OHD3) in each patient. The BMD was determined by dual-energy X-ray absorptiometry (DXA) at the lumbar spine and femoral neck.

Results: Osteoporosis was documented in 10 IBD patients (13.2\%), while osteopenia in 35 of them (46.1\%). Patients with CD have significantly lower femoral Z score than patients with UC. Femoral Z score was strongly associated with disease duration, and in CD patients suffering from stricturing form, with ileic or ileocolic location and history of proctocolectomy or total colectomy. Patients with osteoporosis had a significantly lower level of 25-OHD3 than patients with normal BMD.

Conclusion: Patients with long disease duration and those suffering from stricturing form of CD with ileic/ileocolic location and history of proctocolectomy/total colectomy are at higher risk of developing osteoporosis than other IBD patients. The high proportion of osteopenia/osteoporosis in our study underlines the importance of BMD measurement in all IBD patients as a base for initiating the appropriate treatment (Tab. 1, Fig. 3, Ref. 63). Full Text in PDF www.elis.sk.

Key words: Crohn's disease, ulcerative colitis, bone density, osteoporosis, risk factors, vitamin D deficiency.
\end{abstract}

\begin{abstract}
Abbreviations: $\mathrm{CD}$ - Crohn's disease, BMD - bone mineral density, BMI - body mass index, IBD - inflammatory bowel disease, CI - confident interval, DXA - dual-energy X-ray absorptiometry, ECLIA - electrochemiluminescence immunoassay, SD - standard deviation, sIBDQ - short inflammatory bowel disease questionnaire, $\mathrm{UC}$ - ulcerative colitis

Inflammatory bowel disease (IBD), i.e. Crohn's disease (CD) and ulcerative colitis (UC), are chronic inflammatory intestinal diseases. Extraintestinal complications of IBD affecting the musculosceletal system are frequent, occurring in $20-50 \%$ of patients (1). Osteoporosis and increased risk of fractures (RR 1.4 versus general population) are a serious problem $(2,3,4)$. The prevalence of osteopenia in IBD has been reported in $22-77 \%$ of patients and osteoporosis in a range of $12-42 \%(5-7)$.
\end{abstract}

Department of Internal Medicine, Division of Gastroenterology and Hepatology, University Hospital and Faculty of Medicine, Comenius University, Bratislava Ruzinov, Slovakia

Address for correspondence: E. Miznerova, MD, Vth Internal Clinic, Division of Gastroenterology and Hepatology, University Hospital Bratislava, Ruzinovska 6, SK-826 06 Bratislava, Slovakia. Phone/Fax: +421.910955997

Acknowledgments: This work was supported by grant from Ministry of Health of Slovak Republic 2007/19-UK-02.
The etiology and exact mechanism of bone mass loss in IBD has not been properly clarified. There are several possible risk factors such as age $(8,9)$, low body mass index $(\mathrm{BMI})(8,10)$, malabsorption, vitamin $\mathrm{D}$ and calcium deficiencies $(11,12)$, bowel resection $(9,13)$, hypogonadism, corticosteroid treatment $(9,12,13,14,15)$, smoking (16), reduced physical activity and genetic factors (17).

The results of studies evaluating the possible risk factors for osteoporosis are various. The study of Tsironi et al on 122 IBD patients documented several independent risk factors for low BMD, namely age $\geq 55$ years (OR 5.08, 95\% CI 1.90-13.57, $\mathrm{p}=0.001$ ), cumulative lifetime dose of prednisolon $\geq 5 \mathrm{~g}$ (OR 3.41, 95\% CI 1.50-7.73, $\mathrm{p}=0.004$ ) and low BMI (8). Study of van Hogenzad on $145 \mathrm{CD}$ patients shows than the ileum resection was the most predictive factor for osteoporosis: RR 3.84 (CI 1.24-9.77, $\mathrm{p}=0.018$ ), followed by age: RR 1.05 (CI 1.02-1.08, p<0.001) and current or past glucocorticoid use: RR 1.94 (CI 0.92-4.10, p=0.08) (9). There are several multivariate studies showing also BMI as a significant risk factor for low $\operatorname{BMD}(8,10,18)$. Vitamin D deficiency has been reported more frequently in patients with ulcerative colitis and Crohn's disease compared with healthy population $(19,20)$. In their study, McCarthy et al. documented the correlations between the lower vitamin D status in patients with $\mathrm{CD}$ and elevated levels of markers of bone turnover (21).

Although there is evidence that long-term corticosteroid therapy reduces the $\operatorname{BMD}(9,12,13,14,15,22,23,24)$, some of stud- 
ies have suggested that BMD in IBD is unrelated to corticosteroid use $(25,26,27,28,29)$. Considering the fact that newly diagnosed patients already have a reduced bone mineral density (BMD), there is a strong case for suggesting that demineralization in patients with IBD occurs primarily as a consequence of intestinal inflammation. Activated T-lymphocytes and other inflammatory cells like macrophages lead to the production of various pro-inflammatory cytokines and mediators which interfere with bone regulatory systems like RANK/RANKL/OPG and thus change the rate of bone formation and bone resorption $(30,31,32,33,34)$. These findings suggest that intestinal inflammation itself plays an important role in the development of osteopenia/osteoporosis, and that low BMD cannot be attributed solely to the treatment with steroids.

The aim of our study was to analyze the prevalence of bone density changes in cohort of IBD patients. Further we wanted to study the risk factors associated with decreased BMD that could move us to understanding the etiology of bone loss and thus to identifying IBD patients who are at higher risk of fractures.

\section{Patients and methods}

\section{Study design and patients}

The study cohort consisted of 76 adult patients with IBD (46 with CD, 30 with UC) followed up at the Department of Gastroenterology, University Hospital Bratislava, Ruzinov. The clinical characteristics of the cohort are given in Table 1. All patients included in our study signed an informed consent to the research. The diagnosis of IBD was established on the basis of clinical, radiological, endoscopic and histological findings. The disease duration was calculated as time elapsed from the onset of symptoms, which may have preceded the clinical diagnosis by several years. The data on glucocorticoid use (daily average dose of prednisone or prednisone-equivalent dose in milligrams, cumulative dose of prednisone in grams or prednisone-equivalent dose and total lifetime of using glucocorticoids in months), disease location and clinical behavior according to Montreal classification and details of surgical intervention (ileum and/or colon resection) were obtained from patients' records. Patients filled in a detailed questionnaire concerning the onset of symptoms of IBD and smoking habits. Disease activity was established by a short inflammatory bowel disease questionnaire (sIBDQ) (35). The level of 25-OHD3 was measured by an electrochemiluminescence immunoassay (ECLIA) - Roche and the levels were not corrected for seasonal variation. No patient of the cohort took a substitution of vitamin D3 at the time of measurement of 25-0HD3.

\section{Bone mineral density measurements}

BMD was measured in all 76 patients from our cohort at the lumbar spine (L1-L4) and hip (total hip) by dual X-ray absorbtiometry (DXA - Hologic Discovery). BMD results are expressed in $\mathrm{g} / \mathrm{cm} 2$ and in $\mathrm{T}$ and $\mathrm{Z}$-score. The T score is the number of standard deviations above or below the mean value for young adults of the same sex, whilst the $\mathrm{Z}$ score is the number of standard deviations above or below the age-related mean value. We used The WHO definition for osteopenia/osteoporosis: osteopenia as a T score of $\leq 1$ but $\geq 2.5$, whilst osteoporosis is defined as a T score of -2.5 or lower (36). We decided to use femoral and lumbal $\mathrm{Z}$ score in the analysis of relationship between bone mineral density and observed clinical parameters.

\section{Statistical analysis}

Data are presented as a \pm SD for the normally distributed parameters according to Shapiro-Wilk's test or as a median and interquartile range for data showing departures from normality. Frequencies are expressed as counts and percentages of the total of observations. The standard Student $t$ test and one-way ANOVA with post-hoc Tukey-Kramer test were employed for detailed multiple comparisons between means (for more than two groups) in the case of data showing no departures from normality (according to Shapiro-Wilk's test). Group differences in the variables that showed the right-skewed distribution were analyzed with the relevant nonparametric tests: Mann-Whitney U test, Kruskal-Wallis test (more than two groups) and post-hoc all-pairwise Connover-Inman test. The chi-square or alternatively Fisher's exact test were used to compare the observed frequencies in the investigated variables (groups). Simple regression analysis was employed to estimate linear dependence between dependent variable of interest and the corresponding regressor. To estimate the associations between variables showing departures from normality, we used Spearman rank correlation (rho) (for testing the null hypothesis of independence between two variables). All $p$ values cited are two-sided alternatives; differences resulting in a $p$ value of less or equal to 0.05 were declared statistically significant. For statistical analysis, we employed the statistical program StatsDirect 2.7.8 software.

\section{Characteristics of patients}

Twenty (45.67\%) patients with CD, among whom none had UC, underwent bowel resection. The most frequently performed operation in these cases was the resection of the ileum either in isolation $(n=13)$ or in combination with right hemicolectomy $(n=2)$. Five $C D$ patients underwent proctocolectomy or total colectomy (Tab. 1).

\section{Results}

\section{Prevalence of osteoporosis}

The prevalence of low BMD in our cohort was 45/76 (59.2 \%) patients (Fig. 1).

Osteoporosis was observed in 10/76 (13.2\%) patients, including 7/46 (15.2\%) CD patients and 3/30 (10\%) UC patients. Osteopenia was observed in 35/76 (46\%), including 22/46 (47.8 \%) CD patients and 13/30 (43.3\%) UC patients.

The lumbar spine was more affected than the femoral neck, emphasized by DXA T score below -1 SD (52.6 \% vs $27.6 \%$, $\mathrm{p}=0.0018$ ).

The prevalence of low BMD among patients, who were never been treated with corticosteroids, was $(22.36 \%)$.

There was a significant difference in the femoral $\mathrm{Z}$ score between patients with $\mathrm{CD}(-0.8 \pm 1.05)$ and UC $(0.0 \pm 1.05, \mathrm{p}=0.004)$. 
Tab. 1. Clinical characteristics of the cohort.

\begin{tabular}{|c|c|c|c|}
\hline Clinical characteristic & All cohort $(\mathrm{n}=76)$ & Ulcerative colitis $(\mathrm{n}=30)$ & Crohn disease $(n=46)$ \\
\hline Male/female (\%) & $36 / 40(47 / 53 \%)$ & $15 / 15(50 / 50 \%)$ & $21 / 25(47 / 53 \%)$ \\
\hline Age (range) /yr/ & $36(19-73)$ & $47(19-73)$ & $36(19-70)$ \\
\hline Duration of disease (median, range) /yr/ & $8.2(1.4-41.2)$ & $10.5(1.5-41.2)$ & $7.7(1.4-35.2)$ \\
\hline \multicolumn{4}{|l|}{ Age at diagnosis /yr/ } \\
\hline$\leq 16(\%)$ & $14(18.4 \%)$ & $5(16.7 \%)$ & $9(19.6 \%)$ \\
\hline $17-40(\%)$ & $44(57.9 \%)$ & $11(36.7 \%)$ & $33(71.7 \%)$ \\
\hline$\geq 41(\%)$ & $18(23.7 \%)$ & $14(46.6 \%)$ & $4(5.2 \%)$ \\
\hline \multicolumn{4}{|l|}{ Location of disease } \\
\hline Terminal ileum & - & - & $18(39.1 \%)$ \\
\hline Ileal and colon $(\%)$ & - & - & $7(15.2 \%)$ \\
\hline Colon only (\%) & - & - & $20(43.4 \%)$ \\
\hline Upper GIT & - & - & $1(2.17 \%)$ \\
\hline Proctitis(\%) & - & $8(26.7 \%)$ & - \\
\hline Distal colitis (\%) & - & $6(20 \%)$ & - \\
\hline Pancolitis (\%) & - & $16(53.3 \%)$ & - \\
\hline \multicolumn{4}{|l|}{ Clinical behaviour in $\mathrm{CD}$} \\
\hline Non-stricturing, non-penetrating & - & - & $14(30.43 \%)$ \\
\hline Stricturing & - & - & $14(30.43 \%)$ \\
\hline Penetrating & - & - & $18(39.13 \%)$ \\
\hline \multicolumn{4}{|l|}{ Severity in UC } \\
\hline Mild & - & $10(33.3 \%)$ & - \\
\hline Moderate & - & $12(30 \%)$ & - \\
\hline Severe & - & $8(26.7 \%)$ & - \\
\hline History of bowel resection & $20(26.3 \%)$ & 0 & $20(45.67 \%)$ \\
\hline Ever smokers & $18(24 \%)$ & $11(36.7 \%)$ & $7(15.21 \%)$ \\
\hline History of glucocorticoid treatment & $50(65.8 \%)$ & $21(70 \%)$ & $29(63 \%)$ \\
\hline Daily average dose of prednisone (mg)(median, range) & $16(0-32)$ & $17.3(0-26)$ & $15(0-32)$ \\
\hline Cumulative dose of prednisone* $(\mathrm{g})($ median, range) & $2(0-42)$ & $2.6(0-42)$ & $1.8(0-16.8)$ \\
\hline Total lifetime of using glucocorticoids (in months) & $7(0-121)$ & $9(0-28)$ & $6(0-121)$ \\
\hline $25-\mathrm{OH}$ vitamin $\mathrm{D} 3 * *$ (median,range) & $18.6(0-35.1)$ & $17.9(0-35.1)$ & $18.6(7.8-46)$ \\
\hline Femoral Z score (median, range) & $-0.6(-3.7-2.3)$ & $-0.3(-1.8-2.3)$ & $-0.9(-3.7-2.1)$ \\
\hline Lumbal Z score (median, range) & $-0.85(-3.8-2.2)$ & $-0.3(-3.7-2.2)$ & $-1.0(-3.8-1.5)$ \\
\hline
\end{tabular}

*The steroid dose is expressed as grams of prednisone or as prednisone-equivalent dose.

** serum level of 25-OH vitamin D3 in $\mathrm{ng} / \mathrm{ml}$, yr: year

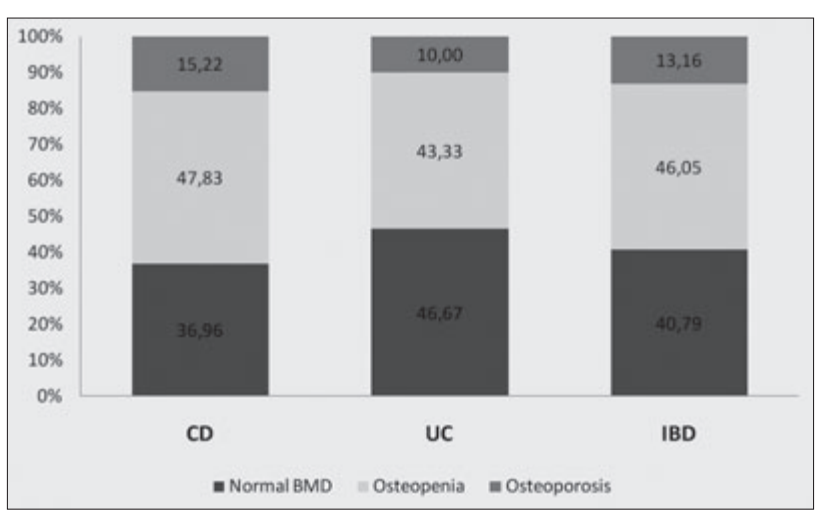

Fig. 1. Prevalence of osteopenia and osteoporosis in 76 IBD patients determined by DXA at lumbar spine and femoral neck.

\section{Univariate analysis of clinical risk factors}

\section{All IBD patients}

There was a significant difference correlation between the femoral $\mathrm{Z}$ score and the duration of disease $(\mathrm{r}=-0.265, \mathrm{p}=0.02)$. Subgroup of CD patients

Significantly lower femoral $\mathrm{Z}$ score had CD patients with stricturing type of disease compared to non-stricturing, non-penetrating (median Z score $-1.25 \mathrm{vs}-0.35 \mathrm{SD}, \mathrm{p}=0.007$ ) or penetrating type of disease (median Z score-1.25 vs $-0.5 \mathrm{SD}, \mathrm{p}=0.04$ ) and those with location of disease at ileum, or ileocolon comparing to colon location (ileum vs colon : medians $Z$ score -0.85 vs $-0.1, p=0.006$; ileocolon vs colon : medians $Z$ score -0.75 vs $-0.1, p=0.009$ ) (Figs 2 and 3 ).

Patients with CD who had undergone proctocolectomy or total colectomy had significantly low medians of femoral $\mathrm{Z}$ score compared with patients with intact gut $(-0.4$ vs $-0.9, p=0.005)$.

CD patients with ileum resection isolated or with right hemicolectomy had a higher tendency to lower medians of $Z$ score than patients with intact gut, but these findings have not been statistically significant $(\mathrm{p}=0.09)$.

\section{Subgroup of UC patients}

There was no significant difference between Z score of hip/ lumbal spine in UC after dividing patients according to location and behavior of the disease.

In all IBD there was no relationship between Z score of hip/ lumbal spine and age, sex, smoking habits, sIBDQ, history of oral glucocorticoid use ever, cumulative steroid dose of prednisone and total lifetime use of glucocorticoids in months. We found a significant positive correlation between the average dose of prednisone and femoral $\operatorname{BMD}(r=0.27, \mathrm{p}=0.025)$. 


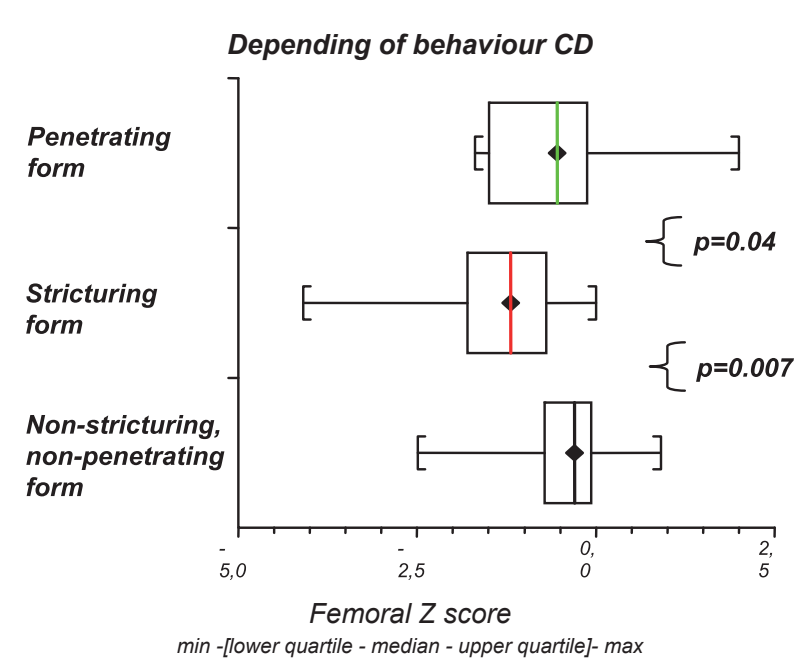

Fig. 2. Box \& whisker plot of medians of femoral $Z$ scores.

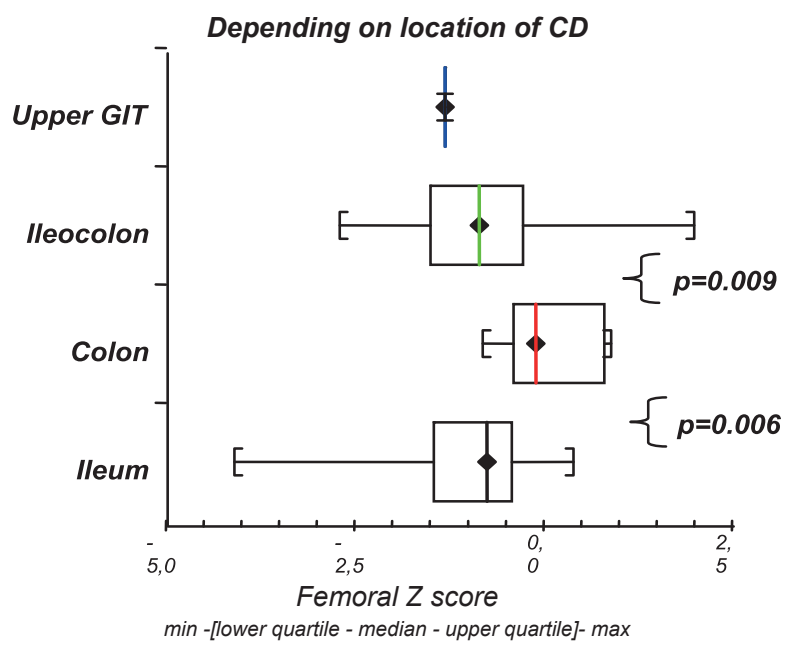

Fig. 3. Box \& whisker plot of medians of femoral $Z$ scores.

Analysis of 25-OHD3

There were $69 / 76$ (91.10\%) IBD patients with vitamin D3 deficiency $(<30 \mathrm{ng} / \mathrm{ml})$. Very low $(<10 \mathrm{ng} / \mathrm{ml})$ level of $25-\mathrm{OHD} 3$ was observed in 13/76 (9.6\%) patients. No difference in level of 25-OHD3 was found between CD and UC.

IBD patients with osteoporosis had a significantly lower serum level of 25-OHD3 than patients with normal bone density (14.2 vs $17.5 \mathrm{ng} / \mathrm{ml}, \mathrm{p}=0.02$ ).

\section{Discussion}

Inflammatory bowel disorders are associated with several factors potentially deterious to the skeleton but the exact relationship between this cytokine-mediated disorder and increased risk of osteoporosis and fractures remains unclear. Moreover, the results of studies dealing with risk factors for reduced BMD in IBD are very controversial. The questions we posed in this study were aimed at assessing the prevalence of osteoporosis in our cohort of IBD patients, as well as at indentifying the clinical features of IBD mostly associated with bone demineralization.

The focus of our study is limited in several aspects. Firstly, we did not apply strict exclusion criteria, mostly as to older population and postmenopausal women. This selection bias could have shifted the ratio of rates of altered bone density in lumbal spine and those of hip towards the former. Secondly, the relatively small size of the study group did not enable us to analyze fractures and multivatiare analysis. Mainly in UC it could affect the results after categorizing the patients to subgroups according to behavior and location of disease. Other weakness of our study stems from the fact that we did not include in it the analysis of effect of azathioprin or biologics on bone mineral density. As is known from recent literature, this immunosuppressive therapy, mostly anti-TNF therapy, may have a positive influence upon bone turnover in IBD patients $(37,38)$.

We found $59 \%$ of IBD patients to be affected by osteopenia and $13 \%$ of patients to be affected by osteoporosis. This is comparable with recent studies where the prevalence of osteoporosis ranged between 12 to $15 \%(7,8,10,13)$. Other studies reported even higher prevalence of osteoporosis in IBD, namely of around 26 to $40 \%(5,28,29)$. As a possible explanation we suggest a higher rate of postmenopausal women in one study (5) or higher percentage of patients under long-term glucocorticoids therapy in cohorts of older studies $(28,29)$ when compared to our study.

It should be noted, that the proportion of IBD patients with osteopenia in our study reached $59 \%$. This underlines the importance of careful assessment of all IBD patients for BMD as well as subsequent initiation of appropriate preventive treatment in those with pathological BMD. Recent literature contains clear evidence of the clinical benefit from bisphosphonates in osteoporosis associated with IBD, while calcium and vitamin D should remain the baseline treatment in osteopenic and osteoporotic patients $(39,40)$.

In our IBD cohort, the lumbar spine was found to be affected more often by pathological BMD than hip. There are just few studies with the same findings $(13,41,42)$; most of published studies report higher prevalence of osteoporosis at the femoral neck $(9$, $28,29,43)$. This discrepancy could have been influenced by a selected bias of our tertiary gastroenterologic center.

Patients with CD had a significantly lower femoral Z-score than patients with UC. This finding is confirmed by other studies $(7,18,27,44)$. Jahnsen et al (45) reported that mean Z-scores were significantly lower in patients with CD compared to patients with UC or healthy patients, while the impact of glucocorticoid treatment leading to low BMD seems to be more significant in UC (44).

In agreement with de Jong DJ et al (41) and other studies (29, $46,47,48)$ we confirmed a significant negative correlation between BMD and disease duration in both diagnoses. The duration of disease may have a measurable impact on bone metabolism in IBD for several reasons including chronic systemic inflammation and drug therapy. Corticosteroids are more often given to patients with frequent relapse of the disease but an increased level of inflammatory cytokines seems to be an important independent risk factor for accelerated bone loss $(49,50)$.

The valuable asset of our study is the analysis of behavior and location of CD with BMD. These findings are not yet well known 
in literature. In our study, the stricturing form of disease was significantly more associated with lower $\mathrm{Z}$ score than its non-penetrating, non-stricturing or penetrating form. We suggest that these data may result from a reduced food intake related to intestinal obstruction, higher rate of malabsorption, longstanding intestinal inflammation and longer disease duration occurring typically in the stricturing form of CD.

Location of disease may contribute to low BMD. There is a report of lower BMD in CD patients with small bowel disease (47) although other studies failed to show such effects $(9,13,16,40)$. Our study documented no relationship between BMD and location of UC; however the location of CD in ileum or ileocon, typically associated with the stricturing form, was in strong correlation with lower femoral Z score.

Patients of our cohort who had undergone bowel resections had significantly lower medians of $Z$ score compared with patients with intact gut. In $\mathrm{CD}$, the highest risk was mostly associated with proctocolectomy or total colectomy often performed in patients with severe disease activity. CD patients with ileum resection isolated or with right hemicolectomy had a trend for lower Z score than patients with intact gut but these findings have not been statistically significant. Results of studies evaluating the bowel surgery as a potential risk factor for developing osteoporosis are controversial. In several published studies, the history of bowel resection is not considered as a risk factor $(16,28,46)$, whereas other studies assessing patients who had undergone ileal resection reported that ileum resection was one of the predictive factors for osteoporosis in patients with CD $(9,13,41,47)$.

The skeletal effects of glucocorticoids are well documented with the main brunt of bone loss observed at trabecular sites (23, $24,51,52)$. The role of glucocorticoids in the pathogenesis of osteoporosis especially in IBD is complex. Whilst some studies have shown a clear relationship between lifetime corticosteroid dose in IBD and vertebral fracture rate $(4,52)$ or low BMD (14, $16,43,45,47)$ other studies have suggested that BMD is unrelated to corticosteroid use $(25,26,27,28,29)$. Our study did not find a negative relationship between the cumulative or total lifetime dose of glucocorticoids and BMD, moreover almost $23 \%$ of patients with osteopenia/osteoporosis have never used glucocorticoids during their disease. We also documented a significant positive correlation between the average dose of prednisone and femoral BMD implicating that intestinal inflammation itself probably plays an important role in the development of osteopenia/osteoporosis, and that low femoral BMD cannot be attributed solely to treatment with glucocorticoids. Recent studies on patients with rheumatoid arthritis, a disease with analogical effect of chronic inflammation on bone loss due to production of pro/inflammatory mediators interfering with bone regulatory systems, have even shown a protective effect of long-term low-dose prednisone on inflammation and $\operatorname{BMD}(53,54)$.

The other important finding of our study was that IBD patients with osteoporosis had a significantly lower serum level of 25OHD3 than patients with normal bone density. There are several possible explanations for the relationship between vitamin D3, $\mathrm{BMD}$ and disease activity. It may be a consequence of reduced efficiency of intestinal absorption of vitamin D, disrupted enterohepatic circulation, reduced dietary intake or reduced sun exposure $(55,56)$, but it can also be a pathological effect of low vitamin D3 on immune system and therefore disease activity $(59,60)$. Poor vitamin D status has already been linked to auto-immune diseases like diabetes type 1, multiple sclerosis, rheumatoid arthritis, as well as $\operatorname{IBD}(55,59,60)$. We documented a high percentage of vitamin D3 deficiency with no difference between CD and UC. Very low $(<10 \mathrm{ng} / \mathrm{ml})$ level of $25-\mathrm{OHD} 3$ of was observed in nearly $10 \%$ of IBD patients. The hypothesis that vitamin D deficiency is not only a consequence but also a cause playing an important role in the development of intestinal inflammatory process, is recently supported by findings of the essential function of vitamin D receptors (VDRs). The VDRs contribute to the protection of colonic mucosa by regulating the intestinal homeostasis (62). Although a significant progress has been achieved concerning the role of vitamin $\mathrm{D}$ and its receptor, the exact mechanism is not yet fully understood and its study could lead to interesting findings concerning the pathological immune response in $\operatorname{IBD}(61,62,63)$.

In conclusion we confirmed high prevalence of osteopenia/ osteoporosis among IBD patients. Reduced BMD, especially in total hip, was strongly associated with the duration of disease and low serum level of vitamin D3. The most important finding of our study was that the stricturing form and ileic or ileocolic locations of CD appear to be the major risk for bone loss relating probably to intestinal obstruction, longstanding intestinal inflammation and longer duration typically occurring in this form of CD.

Our study found no negative relationship between glucocorticoids treatment and BMD, moreover we documented a significant positive correlation between the average dose of prednisone and femoral BMD implicating that intestinal inflammation itself probably plays an important role in bone loss, and that a low femoral BMD cannot be attributed solely to treatment with glucocorticoids.

On the basis of our findings we conclude that demineralization of bone in IBD patients occurs primarily as a consequence of intestinal and systemic inflammation, and secondarily as a consequence of complex relationship between disease severity, location, malabsorption, drug therapy and other risk factors.

\section{References}

1. Rodriguez-Reyna TS, Martinez-Reyes C, Yamamoto-Furusho JK. Rheumatic manifestations of inflammatory bowel disease. World J Gastroenterol 2009; 15: 5517-5524.

2. Payer J, Killinger Z, Duris I. Bone changes in gastrointestinal diseases. Bratis1 Lek Listy 1998; 99: 20-22.

3. Bernstein CN, Blanchard JF, Leslie W, Wajda A, Yu BN. The incidence of fracture among patients with inflammatory bowel disease. A population-based cohort study. Ann Intern Med 2000; 133: 795-799.

4. Card T, West J, Hubbard R, Logan RF. Hip fractures in patients with inflammatory bowel disease and their relationship to corticosteroid use: a population based cohort study. Gut 2004; 53: 251-255.

5. Etzel JP, Larson MF, Anawalt BD, Collins J, Dominitz JA. Assessment and management of low bone density in inflammatory bowel disease and performance of professional society guidelines. Inflamm Bowel Dis 2011; 17: 2122-2129. 
6. van Hogezand RA HN. Skeletal morbidity in inflammatory bowel disease. Scand J Gastroenterol Suppl 2006: 59-64.

7. Ezzat Y, Hamdy K. The frequency of low bone mineral density and its associated risk factors in patients with inflammatory bowel diseases. Int $\mathrm{J}$ Rheum Dis 2010; 13: 259-265.

8. Tsironi E, Hadjidakis D, Mallas E, Tzathas C, Karamanolis DG, Ladas SD. Comparison of T- and Z-score in identifying risk factors of osteoporosis in inflammatory bowel disease patients. J Musculoskelet Neuronal Interact 2008; 8: 79-84.

9. van Hogezand RA BD, Zwinderman AH, McCloskey EV, Griffioen G, Hamdy NA. Ileum resection is the most predictive factor for osteoporosis in patients with Crohn's disease. Osteoporos Int 2006; 17: 535-534.

10. Bartram SA, Peaston RT, Rawlings DJ, Walshaw D, Francis RM, Thompson NP. Mutifactorial analysis of risk factors for reduced bone mineral density in patients with Crohn's disease. World J Gastroenterol 2006; 12 : 5680-5686.

11. Cashman KD. Altered bone metabolism in inflammatory disease: role for nutrition. Proc Nutr Soc 2008; 67: 196-205.

12. Bours PH, Wielders JP, Vermeijden JR, van de Wiel A. Seasonal variation of serum 25-hydroxyvitamin D levels in adult patients with inflammatory bowel disease. Osteoporos Int 2011; 22: 2857-2867.

13. Frei P, Fried M, Hungerbuhler V, Rammert C, Rousson V, Kullak-Ublick GA. Analysis of risk factors for low bone mineral density in inflammatory bowel disease. Digestion 2006; 73: 40-46.

14. Dear KL, Compston JE, Hunter JO. Treatments for Crohn's disease that minimise steroid doses are associated with a reduced risk of osteoporosis. Clin Nutr 2001; 20: 541-546.

15. Cino M, Greenberg GR. Bone mineral density in Crohn's disease: a longitudinal study of budesonide, prednisone, and nonsteroid therapy. Am J Gastroenterol 2002; 97: 915-921.

16. Silvennoinen JA, Lehtola JK, Niemela SE. Smoking is a risk factor for osteoporosis in women with inflammatory bowel disease. Scand $\mathbf{J}$ Gastroenterol 1996; 31: 367-371.

17. Schulte CM, Dignass AU, Goebell H, Roher HD, Schulte KM. Genetic factors determine extent of bone loss in inflammatory bowel disease. Gastroenterology 2000; 119: 909-920.

18. Van Schaik FD, Verhagen MA, Siersema PD, Oldenburg B. High prevalence of low bone mineral density in patients with Inflammatory Bowel Disease in the setting of a peripheral Dutch hospital. J Crohns Colitis 2008; 2: 208-213.

19. Leslie WD, Miller N, Rogala L, Bernstein CN. Vitamin D status and bone density in recently diagnosed inflammatory bowel disease: the Manitoba IBD Cohort Study. Am J Gastroenterol 2008; 103: 1451-1459.

20. Lagishetty V, Misharin AV, Liu NQ et al. Vitamin D deficiency in mice impairs colonic antibacterial activity and predisposes to colitis. Endocrinology 2010; 151: 2423-2432.

21. McCarthy D, Duggan P, O'Brien M et al. Seasonality of vitamin D status and bone turnover in patients with Crohn's disease. Aliment Pharmacol Ther 2005; 21: 1073-1083.

22. Lo Cascio V, Bonucci E, Imbimbo B et al. Bone loss after glucocorticoid therapy. Calcif Tissue Int 1984; 36: 435-438.

23. van Staa TP, Abenhaim L, Cooper C, Zhang B, Leufkens HG. Public health impact of adverse bone effects of oral glucocorticoids. Br J Clin Pharmacol 2001; 51: 601-607.
24. Kanis JA, Johansson H, Oden A et al. A meta-analysis of prior corticosteroid use and fracture risk. J Bone Miner Res 2004; 19: 893-899.

25. Dinca M, Fries W, Luisetto G et al. Evolution of osteopenia in inflammatory bowel disease. Am J Gastroenterol 1999; 94: 1292-1297.

26. Staun M, Tjellesen L, Thale M, Schaadt O, Jarnum S. Bone mineral content in patients with Crohn's disease. A longitudinal study in patients with bowel resections. Scand J Gastroenterol 1997; 32: 226-232.

27. Szathmari M, Pronai L, Tulassay Z. Altered bone metabolism in inflammatory bowel disease. Am J Gastroenterol 1998; 93: 848-849.

28. Bjarnason I, Macpherson A, Mackintosh C, Buxton-Thomas M, Forgacs I, Moniz C. Reduced bone density in patients with inflammatory bowel disease. Gut 1997; 40: 228-233.

29. Pollak RD, Karmeli F, Eliakim R, Ackerman Z, Tabb K, Rachmilewitz D. Femoral neck osteopenia in patients with inflammatory bowel disease. Am J Gastroenterol1998; 93: 1483-1490.

30. Moschen AR, Kaser A, Enrich B, Ludwiczek O, Gabriel M, Obrist P. The RANKL/OPG system is activated in inflammatory bowel disease and relates to the state of bone loss. Gut 2005; 54: 479-487.

31. Ross FP. M-CSF, c-Fms, and signaling in osteoclasts and their precursors. Ann N Y Acad Sci 2006; 1068: 110-116.

32. Rogers A, Eastell R. Circulating osteoprotegerin and receptor activator for nuclear factor kappaB ligand: clinical utility in metabolic bone disease assessment. J Clin Endocrinol Metab 2005; 90: 6323-6331.

33. Bernstein CN, Sargent M, Leslie WD. Serum osteoprotegerin is increased in Crohn's disease: a population-based case control study. Inflamm bowel dis 2005 ; 11 : $325-330$.

34. Hofbauer LC, Lacey DL, Dunstan CR, Spelsberg TC, Riggs BL, Khosla S. Interleukin-1beta and tumor necrosis factor-alpha, but not interleukin-6, stimulate osteoprotegerin ligand gene expression in human osteoblastic cells. Bone 1999; 25: 255-259.

35. Irvine EJ, Zhou Q, Thompson AK. The Short Inflammatory Bowel Disease Questionnaire: a quality of life instrument for community physicians managing inflammatory bowel disease. CCRPT Investigators. Canadian Crohn's Relapse Prevention Trial. Am J Gastroenterol 1996; 91: 1571-1578.

36. World Health Organization (1994). Assessment of fracture risk and its application to screening for postmenopausal osteoporosis. WHO Technical Report Series 843.

37. Ryan BM, Russel MG, Schurgers L et al. Effect of antitumour necrosis factor-alpha therapy on bone turnover in patients with active Crohn's disease: a prospective study. Aliment Pharmacol Ther 2004; 20: 851-857.

38. Bernstein M, Irwin S, Greenberg GR. Maintenance infliximab treatment is associated with improved bone mineral density in Crohn's disease. Am J Gastroenterol 2005; 100: 2031-2035.

39. Henderson S, Hoffman N, Prince R. A double-blind placebo-controlled study of the effects of the bisphosphonate risedronate on bone mass in patients with inflammatory bowel disease. Am J Gastroenterol 2006; 101: 119-123.

40. Palomba S, Manguso F, Orio F Jr et al. Effectiveness of risedronate in osteoporotic postmenopausal women with inflammatory bowel disease: a prospective, parallel, open-label, two-year extension study. Menopause 2008; 15: 730-736.

41. de Jong DJ, Mannaerts L, van Rossum LG, Corstens FH, Naber AH. Longitudinal study of bone mineral density in patients with Crohn's disease. Dig Dis Sci 2003; 48: 1355-9135. 
42. A Habtezion, MS. Silverberg, R Parkes, S Mikolainis, AH Steinhart. Risk Factors for Low Bone Density in Crohn's Disease. Inflamm Bowel Dis 2002; 8: 87-92.

43. Bernestein CN, Seeger LL., Sazre J.W., Anton, PA., Artinian, L. Shanahan, F. Decreased bone density in inflammatory bowel disease is related to corticosteroid use and not disease diagnosis. J Bone Miner Res 1995; 10: 250-256.

44. Ghosh S, Cowen S, Hannan WJ, Ferguson A. Low bone mineral density in Crohn's disease, but not in ulcerative colitis, at diagnosis. Gastroenterology 1994; 107: 1031-1039.

45. Jahnsen J, Falch JA, Aadland E, Mowinckel P. Bone mineral density is reduced in patients with Crohn's disease but not in patients with ulcerative colitis: a population based study. Gut 1997; 40: 313-319.

46. Robinson RAA, Iqbal SJ et al. Osteoporosis and determinants of bone density in patients with Crohn's disease. Dig Dis Sci 1998; 43: 2500-2506.

47. Ardizzone SB, Bettica P et al. Altered bone metabolism in inflammatory bowel disease: there is a difference between Crohn's disease and ulcerative colitis. J Intern Med 2000; 247: 63-70.

48. Dresner-Pollak R, Karmeli F, Eliakim R, Ackerman Z, Rachmilewitz D. Increased urinary N-telopeptide cross-linked type 1 collagen predicts bone loss in patients with inflammatory bowel disease. Am J Gastroenterol 2000; 95: 699-704

49. Turk N, Cukovic-Cavka S, Korsic M, Turk Z, Vucelic B. Proinflammatory cytokines and receptor activator of nuclear factor kappaB-ligand/ osteoprotegerin associated with bone deterioration in patients with Crohn's disease. Eur J Gastroenterol Hepatol 2009; 21: 159-166.

50. Alesci S, De Martino MU, Ilias I, Gold PW, Chrousos GP. Glucocorticoid-induced osteoporosis: from basic mechanisms to clinical aspects. Neuroimmunomodulation 2005; 12: 1-19.

51. Shaker JL, Lukert BP. Osteoporosis associated with excess glucocorticoids. Endocrinol Metab Clin North Am 2005; 34: 341-345.

52. van Staa TP, Cooper C, Brusse LS, Leufkens H, Javaid MK, Arden NK. Inflammatory bowel disease and the risk of fracture. Gastroenterology 2003 ; 125: 1591-1597.
53. Tengstrand B, Larsson E, Klareskog L, Hafstrom I. Randomized withdrawal of long-term prednisolone treatment in rheumatoid arthritis: effects on inflammation and bone mineral density. Scand J Gastroenterol 2007; 36: 351-358.

54. Engvall IL, Svensson B, Tengstrand B, Brismar K, Hafstrom I. Impact of low-dose prednisolone on bone synthesis and resorption in early rheumatoid arthritis: experiences from a two-year randomized study. Arthritis Res Ther 2008; 10: R128.

55. Gilman J, Shanahan F, Cashman KD. Determinants of vitamin D status in adult Crohn's disease patients, with particular emphasis on supplemental vitamin D use. Eur J Clin Nutr 2006; 60: 889-896.

56. Holick MF. Vitamin D deficiency. N Engl J Med 2007; 357: 266-281.

57. Froicu M, Weaver V, Wynn TA, McDowell MA, Welsh JE, Cantorna MT. A crucial role for the vitamin D receptor in experimental inflammatory bowel diseases. Mol endocrinol 2003; 17: 2386-2392.

58. Joseph AJ, George B, Pulimood AB, Seshadri MS, Chacko A. 25 $(\mathrm{OH})$ vitamin D level in Crohn's disease: association with sun exposure \& disease activity. Indian J Med 2009; 130: 133-137.

59. Cantorna MT, Zhu Y, Froicu M, Wittke A. Vitamin D status, 1,25-dihydroxyvitamin D3, and the immune system. Am J Clin Nutr 2004; 80 : 1717S-1720S.

60. Leslie WD, Miller N, Rogala L, Bernstein CN. Vitamin D status and bone density in recently diagnosed inflammatory bowel disease: the Manitoba IBD Cohort Study. Am J Gastroenterol 2008; 103: 1451-1459.

61. Wu S, Liao AP, Xia Yet al. Vitamin D receptor negatively regulates bacterial-stimulated NF-kappaB activity in intestine. American J Pathol 2010; 177: 686-697.

62. Lagishetty V, Misharin AV, Liu NQ et al. Vitamin D deficiency in mice impairs colonic antibacterial activity and predisposes to colitis. Endocrinol 2010; 151: 2423-2432.

63. Hughes DJ, McManus R, Neary P, O'morain C, O'sullivan M. Common variation in the vitamin $\mathrm{D}$ receptor gene and risk of inflammatory bowel disease in an Irish case-control study. Eur J Gastroenterol Hepatol 2011; 23: 807-812. 